\title{
Immunological potential of tertiary lymphoid structures surrounding the primary tumor in gastric cancer
}

\author{
YOSHIHITO YAMAKOSHI, HIROAKI TANAKA, CHIE SAKIMURA, SOTA DEGUCHI, TAKUYA MORI, \\ TATSURO TAMURA, TAKAHIRO TOYOKAWA, KAZUYA MUGURUMA, \\ KOSEI HIRAKAWA and MASAICHI OHIRA
}

Department of Gastroenterological Surgery, Osaka City University Graduate School of Medicine, Abeno-ku, Osaka 545-8585, Japan

Received November 18, 2019; Accepted March 5, 2020

DOI: 10.3892/ijo.2020.5042

\begin{abstract}
Tertiary lymphoid structures (TLSs), which consist of B cells, T cells, follicular dendritic cells and high endothelial venules, have recently been found to be associated with effective antitumor immune responses in patients with cancer. Tumor-infiltrating T cells and B cells have each been demonstrated to be associated with survival in patients with cancer. We hypothesized that TLSs, an assembly of immune cells, may be important for the initiation and/or maintenance of $\mathrm{T}$ cell and $\mathrm{B}$ cell responses against tumors. The aim of the present study was to examine the cellular mechanism of B cells in TLSs within gastric cancer and to understand the antitumor immune response of TLSs. Each B cell subset in a tumor was examined using flow cytometry to evaluate $\mathrm{B}$ cell differentiation and the functional status of B cells. In addition, $\mathrm{B}$ cell clonality was investigated by analyzing the $\mathrm{B}$ cell antigen receptor gene using PCR, and the function and formation/maintenance of TLSs were evaluated using reverse transcription-quantitative PCR. Tumor-infiltrating B cells were more differentiated compared with that in distant non-tumor tissues and tumor-draining lymph nodes. The PCR results revealed specific BCR gene expression in tumor-infiltrating B cells. The expression of co-stimulatory factors, CD80 and CD86, was observed, in addition to the constantly expressed major histocompatibility complex molecules (HLA-ABC and HLA-DR). CD70 was expressed in addition to CD27 in both $\mathrm{CD} 20^{+} \mathrm{B}$ cells and $\mathrm{CD} 8^{+} \mathrm{T}$ cells, indicating that these factors are activated together through their interaction. The mRNA expression levels of CCL21, CXCL13, PD-L1, perforin and granzyme B in TLSs was significantly higher compared with that in non-TLSs. The majority of tumor-infiltrating B cells in gastric cancer exist in the form of TLSs around the tumor and
\end{abstract}

Correspondence to: Dr Hiroaki Tanaka, Department of Gastroenterological Surgery, Osaka City University Graduate School of Medicine, 1-4-3 Asahi-machi, Abeno-ku, Osaka 545-8585, Japan E-mail: hiroakitan@med.osaka-cu.ac.jp

Key words: tertiary lymphoid structure, B cell, gastric cancer, anti-tumor immune response, tumor infiltrating lymphocyte have been antigen-sensitized and differentiated, and proliferated in TLSs but not in the lymph nodes. In addition, B cells in TLSs might primarily function as antigen-presenting cells and be associated with the induction of cytotoxic T cells.

\section{Introduction}

Immunotherapy using immune checkpoint inhibitors is associated with improved therapeutic effects in patients with gastric cancer (1). Cytotoxic T cells (CTLs), which differentiate and proliferate from naïve $\mathrm{CD}^{+} \mathrm{T}$ cells, play an important role in the antitumor immune response, such as preventing tumor progression and decreasing the metastatic potential, and tumor-infiltrating $\mathrm{CD} 8^{+} \mathrm{T}$ cells are associated with survival of patients with gastric cancer (2). On the other hand, the role of tumor-infiltrating B cells is controversial. Immature and mature B cells both have the capacity to differentiate into interleukin (IL)10-producing regulatory B cells, and IL10- and/or IL35-producing plasmablasts and/or plasma cells (PCs), which suppress the immune response (3). Previous studies have found a correlation between tumor-infiltrating B cells and favorable clinical outcomes in patients with cancers, such as breast, lung and ovarian cancer (4-6). In another study on hepatocellular carcinoma, there was a significant correlation between CD20 ${ }^{+}$ $\mathrm{B}$ cells and $\mathrm{CD} 8^{+} \mathrm{T}$ cells, and that their coexistence was associated with an increase in the overall and recurrence-free survival rates (7)

We previously reported that B cells formed clusters with $\mathrm{T}$ cells and involved CD21 follicular dendritic cells (FDCs) and high endothelial venules (HEVs), and that these aggregates of immune cells in gastric cancer were identified as tertiary lymphoid structures (TLSs) (8). TLSs develop in numerous pathophysiological conditions, such as infectious diseases, autoimmune and inflammatory disorders, and in transplanted organs $(9,10)$. An adaptive immune response may be generated in TLSs within the acutely infected organ during infection. However, when the infection lasts $>5$ months it becomes chronic, and TLSs are elements of the local inflammatory context, wherein lymphocytic activation may occur, leading to the development of diseases, such as Helicobacter pylori (H. pylori)-induced chronic gastritis (11). It has been reported that TLSs also cause chronic rejection of transplanted 
organs by generating effector and memory cells from naïve $\mathrm{T}$ cells in rat insulin promoter lymphotoxin- $\alpha$ murine model (12). On the other hand, TLSs have been shown to be associated with the activation of antitumor immunity responses in cancer, for example, TLSs in lung cancer tissue are associated with tumor-infiltrating mature DCs and with prolonged 5-year disease-specific survival rate in patients with high TLS compared to those with low TLS $(13,14)$. Furthermore, our previous study revealed that an increase in TLSs was correlated with an increase in the overall survival rate in patients with gastric cancer (8). Several studies have previously reported that TLSs are important in the augmentation of adaptive antitumor immune response, including $\mathrm{T}$ cell induction $(15,16)$, and that they are associated with prolonged the 5-year survival rate in patients with cancer, such as lung, gastric, colorectal and breast cancer, as well as oral squamous cell carcinoma (14-18).

We therefore hypothesized that TLSs could be a key factor in the induction of antigen-specific CTLs. While the mechanisms underlying the formation, maintenance and function of TLSs are currently being explored, the antitumor function of B cells in TLSs remain unclear. In the present study, the cellular mechanism of B cells in TLSs surrounding the primary tumor was examined to understand the association between TLSs and the proliferation of CTLs, which may lead to a new immunotherapeutic platform for gastric cancer.

\section{Materials and methods}

Patients and specimens. The present retrospective study included 226 patients with stage IB-IV gastric cancer who had undergone initial surgical resection without preoperative chemotherapy and radiotherapy at Osaka City University Hospital, (Osaka, Japan) between 2007 and 2010. The mean age of the patients was 66.6 years (range, 22-88 years) and there were $162(71.7 \%)$ males and $64(28.3 \%)$ females. The disease-free survival (DFS) was defined as the time between the date of surgery and recurrence. Pathological TNM staging was recorded for all patients based on the Union for International Cancer Control TNM classification, 7th edition (19). Location, circumference and histological type were determined based on the Japanese classification of gastric carcinoma, 14th edition (20). The specimens collected between 2007 and 2010 were subjected to immunohistochemistry, reverse transcription-quantitative PCR (RT-qPCR) and terminal deoxynucleotidyl-transferase-mediated dUTP nick end labeling (TUNEL) analysis. Fresh gastric cancer specimens from 40 patients with stage IB-IV gastric cancer without preoperative chemotherapy and radiotherapy were obtained immediately after surgical resection between 2016 and 2019 for flow cytometry analysis, the analysis of B cell antigen receptor (BCR) and allogeneic mixed leukocyte reaction (allo-MLR). TLSs in the fresh resected specimens were identified using hematoxylin and eosin (H\&E) staining. Distant non-tumoral tissues, $>3 \mathrm{~cm}$ from tumor tissues and lymph nodes, which were located in the peri gastric wall near the primary tumor, termed tumor-draining lymph nodes (TDLNs) were also obtained from the same resected specimens. Peripheral blood mononuclear cells (PBMCs) were obtained from healthy donors. The present study was performed according to the Declaration of Helsinki and was approved by the Osaka City University Ethics Committee and informed consent was provided by all the patients.

Immunohistochemistry. Immunohistochemistry was performed on 4- $\mu \mathrm{m}$ thick sections from paraffin-embedded (FFPE) tumor blocks, which were obtained from patients with gastric cancer and fixed with $10 \%$ formalin at room temperature for 6-48 h. After incubation at $60^{\circ} \mathrm{C}$ for $10 \mathrm{~min}$, the sections were deparaffinized using xylene and rehydrated in a graded ethanol series (70, 80, 90 and 100\%) for 3 min each time, twice. Endogenous peroxidase activity was blocked with absolute methanol containing 3\% hydrogen peroxide at room temperature for $15 \mathrm{~min}$. After washing the sections in PBS, they were microwaved for $10 \mathrm{~min}$ to achieve antigen retrieval. Non-specific binding was blocked using the non-specific staining blocking reagent, Target Retrieval Solution (Dako; Agilent Technologies, Inc.), which was diluted 10 times with sterile distilled water, and the samples incubated at $95^{\circ} \mathrm{C}$ for $45 \mathrm{~min}$. The sections were subsequently incubated with the primary antibody overnight at $4^{\circ} \mathrm{C}$, following which, they were incubated with the secondary antibody, histofine reagent (pre-diluted; Nichirei Biosciences, Inc.) at room temperature for $10 \mathrm{~min}$, and the signal was visualized using 3-3'-diaminobenzidine, and finally counter-stained with hematoxylin at room temperature for $20 \mathrm{sec}$ before mounting. The primary antibodies used for the immunohistochemical analyses were as follows: mouse anti-CD3 for T cells (clone F7.2.38; 1:50; Dako; Agilent Technologies, Inc.), mouse anti-CD20 for B cells (clone L26; pre-diluted; Dako; Agilent Technologies, Inc.), mouse anti-CD21 for FDCs (clone 413771; pre-diluted; Nichirei Biosciences, Inc.) and anti-CD138 for PCs (clone MI15; 1:50; Dako; Agilent Technologies, Inc.). The primary antibodies were diluted with 5\% BSA (Sigma-Aldrich; Merck KGaA) in PBS. The invasion density of B cells that were CD20-positive following immunostaining was measured using the ImageJ software program (version 15.1; National Institutes of Health), and the mean value of the percentage area in the 3 fields of view was determined. The cut-off value (1.927) was determined by the receiver operating characteristic curve. This value was then used to divide specimens into two groups: TLS rich $(n=105)$ and poor $(n=121)$.

Isolation of lymphocytes. Fresh specimens from 20 patients with gastric cancer were obtained immediately following resection. Approximately $1 \mathrm{~cm}^{3}$ tissue was sampled from the tumor area, the non-tumor area and TDLNs of the resected specimens. The tissues were minced, further pulverized by mixing with a homogenizer and digested in $1 \mathrm{mg} / \mathrm{ml}$ collagenase for $1 \mathrm{~h}$. The cell suspension was filtered with a cell strainer with a $70-\mu$ m nylon mesh (BD Falcon; BD Biosciences) and lymphocytes were then isolated using Ficoll density gradient centrifugation with Ficoll-Paque ${ }^{\mathrm{TM}}$ PLUS (GE Healthcare Life Sciences) at $1,025 \mathrm{x}$ g for $20 \mathrm{~min}$ at $20^{\circ} \mathrm{C}$, with the brakes off (21). PBMCs were also isolated from healthy donors using Ficoll-Paque $^{\mathrm{TM}}$ PLUS (GE Healthcare Life Sciences). For Allo-MLR and BCR analysis, cell sorting was additionally performed using the BD FACSAria ${ }^{\mathrm{TM}}$ (BD Biosciences) III according to the manufacturer's instructions.

Flow cytometry. Flow cytometry was performed to characterize and compare the surface markers of B and T cells in the 
single-cell suspensions of each tissues (tumor tissues, distant non-tumor tissues and TDLNs, obtained from the same fresh resected specimens; $n=20$ ), and PBMCs from the blood of the healthy controls $(n=3)$. To visualize B cells and confirm the differentiation stage in greater detail, the pan-B cell marker CD19 was used, which is expressed in almost all B cell stages, including plasmablasts. Naïve B cells are activated by antigen stimulation in the pre-activated state to become pre-germinal center (GC) B cells, which are converted to GC B cells and then plasmablasts. Memory B cells are in a quiescent state. B cell subsets were classified using immunoglobulin (Ig)D and CD38 as follows: Naïve B cell, CD38(int)/IgD(+); pre-GC B cell, CD38(int)/IgD(+); GC B cell, CD38(int)/IgD(-); plasmablast, CD38(high)/IgD(-); and memory B cell, CD38(-)/IgD(-) $(14,22)$. In blood from a healthy patient, IgD can be clearly distinguished as either positive or negative using flow cytometry, and as CD38 is indistinguishable, the middle area between low and high was determined as intermediate (int). To examine the surface phenotype characteristics of antigen-presenting cells (APCs), the expression of CD20 in differentiated B cells was used. Multiple stainings were performed using fluorescence-labeled monoclonal antibodies, which included PE-Cy ${ }^{\mathrm{TM}}$ 7-labeled anti-CD19 (cat. no. 560911), BB515-labeled anti-CD70 (cat. no. 565156), PE-labeled anti-CD20 (cat. no. 590961) and CD8 (cat. no. 557086); FITC-labeled anti-IgD (cat. no. 562023), HLA-DR (MHC class II; cat. no. 560944) and CD80 (cat. no. 557226); and APC-labeled anti-HLA-ABC (MHC class I; cat. no. 555555), CD27 (cat. no. 561786), CD38 (cat. no. 560980) and CD86 (cat. no. 555660); Fc Block $^{\mathrm{TM}}$ (cat. no. 564220); 7-Amino-Actinomycin D (cat. no. 559925) were purchased from BD Biosciences. In brief, after saturation with BD Fetal Bovine Serum Stain Buffer (BD Biosciences), mononuclear cells were incubated with the primary antibodies or appropriate isotype controls for $30 \mathrm{~min}$ at $4^{\circ} \mathrm{C}$ in the dark. Flow cytometric analysis were performed on the BD FACSAria ${ }^{\mathrm{TM}}$ III (BD Biosciences) according to the manufacturer's instructions. The same procedure was used to evaluate the dilution of carboxyfluorescein succinimidyl ester (CFSE; Thermo Fisher Scientific, Inc.) in Allo-MLR.

Allogeneic-mixed leukocyte reaction (Allo-MLR). B cells isolated from tumor tissues (TLSs area) and non-tumor tissues (non-TLSs area) of the fresh resected specimens as aforementioned were used. $\mathrm{CD}^{+} \mathrm{T}$ cells were isolated from PBMCs of healthy donors using the $\mathrm{CD}^{+} \mathrm{T}$ Cell Isolation kit according to the manufacturer's protocol (Miltenyi Biotec $\mathrm{GmbH}$ ). Allo $\mathrm{CD}^{+} \mathrm{T}$ cells were stained with $5 \mu \mathrm{M}$ CFSE (Thermo Fisher Scientific, Inc.) at $37^{\circ} \mathrm{C}$ for $30 \mathrm{~min}$ and added to the $\mathrm{B}$ cells at a ratio of 5:1 (T:B cells). The cells were then co-cultured in 96-well U-bottom plates (Corning, Inc.) at $37^{\circ} \mathrm{C}$ in a humidified incubator with $5 \% \mathrm{CO}_{2}$. After $24 \mathrm{~h}$, the co-cultures were stained with APC-labeled anti-CD4 (cat. no. 555349; BD Biosciences) for $30 \mathrm{~min}$ at $4{ }^{\circ} \mathrm{C}$ in the dark and the $\mathrm{T}$ cell proliferation was assessed by measuring the dilution of CFSE using flow cytometry and gating of $\mathrm{CD}^{+} \mathrm{T}$ cells.

Analysis of $B$ cell antigen receptor genes. Total RNA was extracted from B cells in the PBMCs of one healthy donor and from the tumor tissues of three patients with gastric cancer using the RNeasy Mini kit according to the manufacturer's protocol (Qiagen, GmbH). cDNA was synthesized using the ReverTra Ace ${ }^{\circledR}$ qPCR RT master mix with gDNA Remover, according to the manufacturer's protocol (Toyobo Life Science, Inc.), using the following protocol: $37^{\circ} \mathrm{C}$ for $15 \mathrm{~min}, 50^{\circ} \mathrm{C}$ for $5 \mathrm{~min}$ and $98^{\circ} \mathrm{C}$ for $5 \mathrm{~min}$. DNA amplification was performed in a total volume of $20 \mu \mathrm{l}$ using Applied Biosystems ${ }^{\mathrm{TM}}$ AmpliTaq Gold ${ }^{\mathrm{TM}} 360$ master mix (Applied Biosystems; Thermo Fisher Scientific, Inc.) with the Human IgG/IgM Library primer set according to the manufacturer's protocol (PROGEN Biotechnik GmbH) (23). The variable heavy chain (VH1-VH3) forward primer was used with the IgG or IgM constant region reverse primer. The following primers were used: VH1 forward, 5'-GAATAGGCCATGGCG5AGGTGCA GCTGGTGCAGTCT-3'; VH2 forward, 5'-GAATAGGCCA TGGCGCAGGT(AG)CAGCTGCAG(GC)AGTC-3'; VH3 forward, 5'-GAATAGGCCATGGCGGAGGTGCAGCTG5T GGAGTCT-3'; IgG reverse, 5'-GAGTCAAGCTTTGGGCCC TTGGTGGA-3'; IgM reverse, 5'-GAGTCAAGCTTTGGGCG CGATGCACT-3'; $\kappa$ variable light chain (vK)1/4 forward, 5'-TACAGGATCCACGCGTAGACATC(GC)(AT)GATGACC CAGTCTCC-3', vK2 forward, 5'-TACAGGATCCACGCGTAG ATATTGTGATGAC(CT)CAG5CTCCA-3'; vK3 forward, 5'-TACAGGATCCACGCGTAGAAATTGT56TGAC7CAGT CTCCA-3', vK reverse, 5'-TGCCAAGCTTGCGGCCGCG AAGACAGATGGTGCAGCACAGT-3'; $\lambda$ variable light chain (VA)1 forward, 5'-TACAGGATCCACGCGTACAGTCTGT G5TGAC6CAGCCGCCCTCA-3'; VA2/5 forward, 5'-TAC AGGATCCACGCGTACAGTCTGCGCTGACTCA(AG)CCG (GC)CCTCT-3; VA3 forward, 5'-TACAGGATCCACGCGTA TCCTATGACCTGACTCAGCCACC5T-3'; VA4a forward, 5'-TACAGGATCCACGCGTATCTGAACTGACTCAGCC (AGT)5CCTC-3'; VA4b forward, 5'-TACAGGATCCACGCG TATCTGAACTGACTCAGGACCCTG5T-3'; VA6 forward, 5'-TACAGGATCCACGCGTA5ATTTTATGCTGACTCAGC CCCCCTCT-3', and VA reverse, 5'-TGCCAAGCTTGCGGCC GCAGAGGA5GG6GGGAACAGAGTGAC-3'. The thermocycling conditions are as follows: denaturation at $95^{\circ} \mathrm{C}$ for $30 \mathrm{sec}$, annealing at $55^{\circ} \mathrm{C}$ for $1 \mathrm{~min}$ and extension at $75^{\circ} \mathrm{C}$ for $1 \mathrm{~min}$ for 30 cycles. The amplified DNA fragments were electrophoresized using $2.0 \%$ agarose and stained with ethidium bromide.

$R T-q P C R$. A total of 12 specimens, which had a high TLS area in the TLS-rich tumor were selected for RT-qPCR. FFPE tissue samples of the TLSs area and non-TLSs area from the same specimens were cut into $20-\mu \mathrm{m}$ thick sections. A total of 4 FFPE sections were used for total RNA isolation using the RecoverAll ${ }^{\mathrm{TM}}$ Total Nucleic Acid Isolation kit according to the manufacturer's protocol, and the cDNA was synthesized using the SuperScript ${ }^{\mathrm{TM}}$ IV VILO $^{\mathrm{TM}}$ master mix with ezDNase ${ }^{\mathrm{TM}}$ enzyme according to the manufacturer's protocol (both Thermo Fisher Scientific, Inc.), using the following protocol: $25^{\circ} \mathrm{C}$ for $10 \mathrm{~min}, 50^{\circ} \mathrm{C}$ for $10 \mathrm{~min}$ and $85^{\circ} \mathrm{C}$ for $5 \mathrm{~min}$. Transcripts were quantified using the StepOnePlus ${ }^{\mathrm{TM}}$ Real-Time PCR System (Thermo Fisher Scientific, Inc.). Reactions were performed in a total of $20 \mu \mathrm{l}$ using TaqMan ${ }^{\mathrm{TM}}$ Fast Advanced master mix (Thermo Fisher Scientific, Inc.) with the following TaqMan ${ }^{\circledR}$ Gene Expression Assays: B2M (cat. no. Hs00187842_m1), IL12A (cat. no. Hs01073447_m1), interferon (IFN) $\gamma$ (cat.no.Hs00989291_m1), CD274 (cat.no.Hs00204257_m1), 
PDCD1LG2(cat.no.Hs00228839_m1),PRF1(cat.no.Hs04931936_ m1), GZMB (cat. no. Hs04261345_m1), CCL21 (cat. no. Hs99999110_m1) and CXCL13 (cat. no. Hs00757930_m1) (all Thermo Fisher Scientific, Inc.) The conditions for qPCR were as follows: Initial denaturation at $95^{\circ} \mathrm{C}$ for $10 \mathrm{~min}$; followed by 40 cycles of $95^{\circ} \mathrm{C}$ for $10 \mathrm{sec}$ and $60^{\circ} \mathrm{C}$ for $1 \mathrm{~min}$. The $2^{-\Delta \Delta \mathrm{Cq}}$ method was used to determine the relative expression of each target gene (24).

TUNEL assay. The TUNEL assay was performed using the In situ Apoptosis Detection kit according to the manufacturer's protocol (Takara Bio, Inc.). In brief, 10 specimens (total 20 specimens) were randomly selected from the TLS rich and poor groups, and the FFPE tissue sections were deparaffinized using xylene and rehydrated in a graded ethanol series (80,90 and 100\%) for 5 min each time, twice. Proteinase K (Fujifilm Wako pure Chemical Corporation) was applied at $400 \mu \mathrm{g} / \mathrm{ml}$ and the sections were incubated at room temperature for $5 \mathrm{~min}$. Endogenous peroxidase activity was blocked with $3 \%$ hydrogen peroxide at room temperature for $15 \mathrm{~min}$. Labeling reaction mixture (consisting of $5 \mu \mathrm{lddT}$ enzyme $+45 \mu 1$ labeling safe buffer; prepared prior to use) was then added to the slide, which was subsequently incubated at $37^{\circ} \mathrm{C}$ in a humidified incubator for $60-90 \mathrm{~min}$. Anti-FITC horseradish peroxidase-conjugate (prediluted; Takara Bio, Inc.) was then added $(70 \mu \mathrm{l})$ and incubated at $37^{\circ} \mathrm{C}$ for $30 \mathrm{~min}$. Finally, the sections were developed with DAB at room temperature for 10-15 min and stained with 3\% methyl green at room temperature for 1-2 min. The tumor sections were scanned at low magnification to select 3 fields of view with a high number of apoptotic cell death at x400 magnification using a fluorescent microscope.

Statistical analysis. All statistical analyses were performed using the JMP software program (version 13; SAS Institute, Inc.). The experiments were repeated at least 3 times, and the data are presented as mean \pm SE. Categorical variables were compared using $\chi^{2}$ tests. Continuous variables were compared using one-way ANOVA with Tukey-Kramer post-hoc test (Fig. 4B), Wilcoxon signed rank test (Figs. 5B, 6Ac and 6Bc; lymph nodes vs. tumor tissues) or Wilcoxon's rank-sum test (Figs. 4C, 5B, 6Ac, 6Bc and 9B). The Kaplan-Meier method and log-rank test were used to compare DFS curves. $\mathrm{P}<0.05$ was considered to indicate a statistically significant difference.

\section{Results}

Confirmation of TLSs in gastric cancer. TLSs were primarily confirmed as aggregates of immune cells at the invasive margin of the tumor, as previously reported (8). Intratumoral TLSs were easily recognized as lymphocyte aggregates in a low-power field of H\&E staining (Fig. 1A and B). TLSs consisted of various types of cells, including B cells, T cells and FDCs. The presence of these cells in TLSs was confirmed using immunohistochemistry with anti-CD20 for B cells, anti-CD3 for T cells, and anti-CD21 for FDCs. B cell clusters were found to be surrounded by a $\mathrm{T}$ cell zone and included FDCs (Fig. 1C-F). Therefore the cluster of $\mathrm{CD} 20^{+} \mathrm{B}$ cells were defined as TLSs and further experimentation was performed. TLSs were observed in normal gastric mucosa, mostly in the muscularis mucosae (Fig. 1G), but intratumoral TLSs were also observed in the vicinity of the tumor (Fig. 1C).

Differentiation and activation of tumor-infiltrating $B$ cell. Associations between paraneoplastic or intratumoral TLSs and clinicopathological features are presented in Table I. Strong TLS expression, with an area $>3.0 \%$ using ImageJ software was observed in $\sim 20 \%$ of patients in the TLS-rich and TLS-poor groups. There was no significant differences between the TLS-rich and poor groups, with the depth of invasion, lymph node metastasis, histological type, or tumor site. However, the DFS was significantly longer in the TLS-rich group compared with that in the TLS-poor group (Fig. 2). Thus, we hypothesized that TLSs might play a key role in the induction of cancer specific cytotoxic $\mathrm{T}$ cells initialized by $\mathrm{B}$ cells. PCs stained with anti-CD138 antibody were detected in the stroma of the tumor, but not within TLSs (Fig. 3A and B), suggesting that the B cells in TLSs might have another function but not the antibody producing PCs. To determine whether or not $\mathrm{B}$ cells are activated in the tumor, double staining with $\mathrm{IgD}$ and $\mathrm{CD} 38$ was performed to determine the degree of $\mathrm{B}$ cell differentiation (Fig. 4A). The proportion of naïve $\mathrm{B}$ cells was further reduced in tumor tissues compared with that in TDLNs, and in non-tumor tissues, and the proportion of GC B cells was increased in tumor tissues, although this was not significant (Fig. 4B). These results indicate that B cells were activated in the tumor tissues. The TLS-rich group showed a lower proportion of naïve B cells and an increase in GC B cells and plasmablasts compared with that in the TLS-poor group. GC B cell activation was strongly observed in the TLS-rich group (Fig. 4C).

Next, to analyze the function of tumor-infiltrating $B$ cells as APCs, $B$ cell phenotypes, including major histocompatibility complex (MHC) and co-stimulatory molecules were investigated. The expression of human leukocyte antigen HLA-ABC, HLA-DR, CD80 and CD86 on CD20 ${ }^{+}$B cells was confirmed. Similarly, to examine the interaction with $\mathrm{T}$ cells, the expression of CD27 and CD70, which are costimulatory systems expressed in the activated state, was confirmed on $\mathrm{CD} 20^{+} \mathrm{B}$ cells and CD8 ${ }^{+} \mathrm{T}$ cells. The expression of CD80/86, a co-stimulatory factor, was observed in addition to the constant expression of MHC (HLA-ABC and HLA-DR) (Fig. 5A). In addition to the expression of $\mathrm{CD} 27$ in $\mathrm{CD} 20^{+} \mathrm{B}$ cells and $\mathrm{CD}^{+} \mathrm{T}$ cells, the expression of $\mathrm{CD} 70$, through which survival and the proliferation of CTLs are promoted, was observed in tumor tissues (Fig. 6Aa and b, and $\mathrm{Ba}$ and b). In the TLS-rich group, the expression of co-stimulatory molecules CD80/86 and $\mathrm{CD} 27 / 70$ in $\mathrm{B}$ cells was higher compared with that in the TLS-poor group (Fig. 5B, 6Ac and Bc). Furthermore, B cells isolated from tumor tissues (TLSs area) induced $\mathrm{T}$ cell proliferation in allo-MLR compared with that in non-tumor tissues (non-TLSs area) (Fig. 7). These results suggest that B cells in the TLS-rich tumor were activated and they induced the proliferation of $\mathrm{T}$ cells.

Clonality of tumor-infiltrating B cells. To evaluate the clonality of B cells, the BCR gene expression in PBMCs from one healthy donor and the tissues of three patients with gastric cancer was compared (Fig. 8). From the healthy donor, the PBMCs amplified the majority of the variable region genes, 

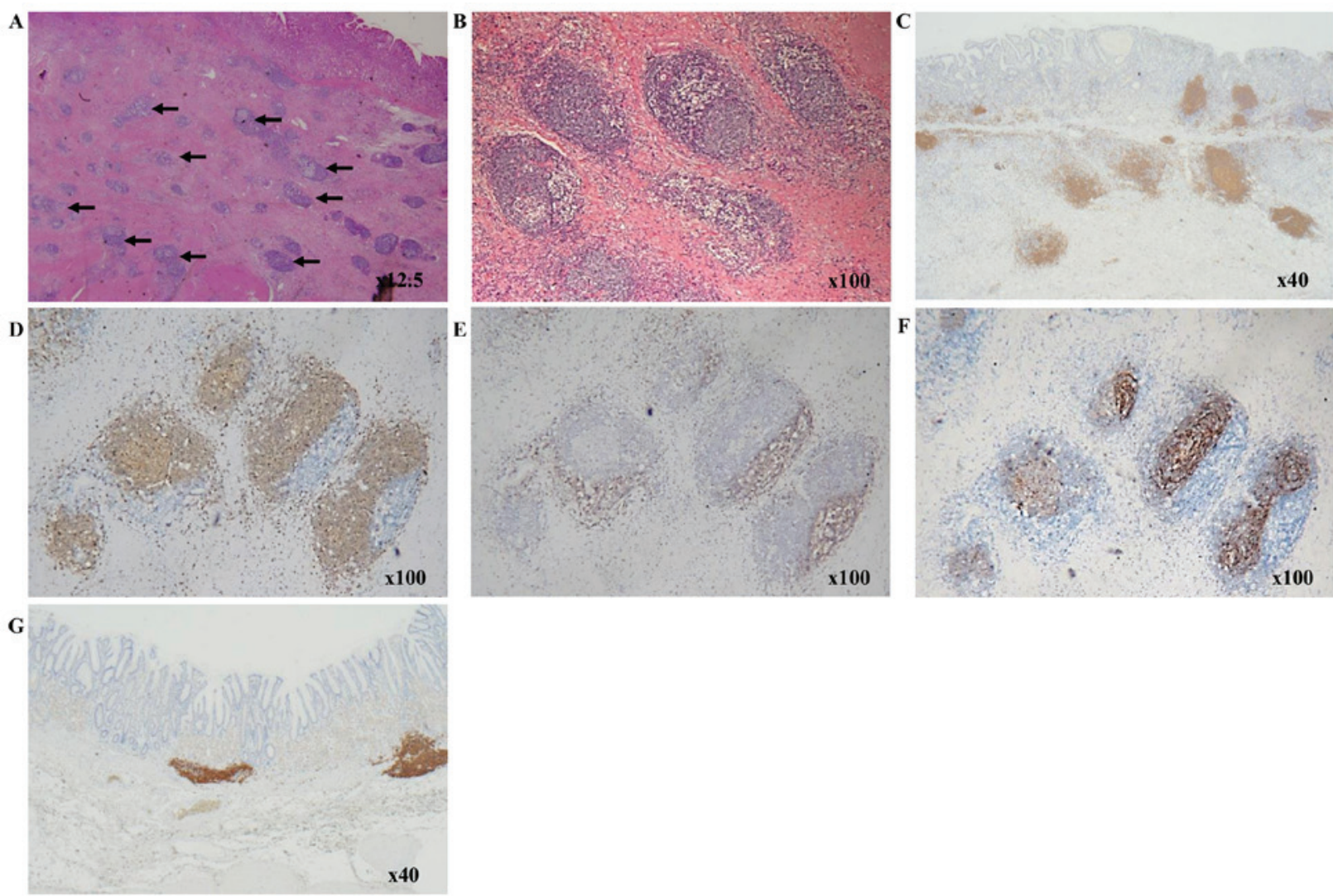

Figure 1. Characterization of immune cells within TLSs. Hematoxylin and eosin staining showing lymphocyte aggregates, as shown by arrows, in gastric cancer at (A) x12.5 and (B) x100 magnification. (C-F) Immunohistochemical staining in patients with gastric cancer. CD20 $0^{+}$B cells form clusters around the tumor at (C) x40 and (D) x100 magnification. (E) A CD3 ${ }^{+} \mathrm{T}$ cell zone is adjacent to the CD20 ${ }^{+} \mathrm{B}$ cell-rich area. (F) The CD20 ${ }^{+} \mathrm{B}$ cell area contained CD21 ${ }^{+}$ follicular dendritic cells. (G) Immunohistochemical staining in a normal stomach, with TLSs in the muscularis mucosa. TLSs, tertiary lymphoid structures.

whereas those from gastric cancer tissues only amplified specific bands, which confirmed that the variable region genes in cancer tissues were deletion or changed, and that this was different in the 3 patients. In tumor tissues, tumor-infiltrating B cells may be antigen-sensitized and some specific B cell clones may proliferate.

Gene expression by immune cells in TLSs. To validate the organization and activation of TLSs, RT-qPCR was performed to detect genes for cytokines, chemokines, cytotoxic substances and immune checkpoint molecules in TLSs area and non-TLSs area of the specimens for the TLS-rich tumor $(n=12)$ (Fig. 9). The lymphocyte chemoattractants, including CCL21 and CXCL13, were chosen as they are required for the activation of B cells (25). The mRNA CCL21 and CXCL13 expression levels were significantly higher in TLSs compared with that in non-TLSs; however, the mRNA expression levels of IL12 and IFN $\gamma$ were not statistically significant, although the mRNA levels of IL12 was higher in TLSs compared with that in non-TLSs. The mRNA expression levels of perforin, Granzyme B and PD-L1 were also significantly higher in TLSs compared with that in non-TLSs; however, there was no significant difference in the expression levels of PD-L2 although the levels were higher in TLSs compared with that in non-TLSs.

Apoptotic cell death in gastric cancer cells. The TUNEL assay was performed to detect apoptotic cells in tumor tissue. Apoptotic cells were stained brown, and positivity in the
TUNEL assay was observed in 7/10 specimens in the TLS-rich group (Fig. 10A and B) but it was only observed in 1/10 specimens of the TLS-poor group (Fig. 10C). There was no marked difference in the appearance of apoptotic cells. However, this result suggests that TLSs may enhance the antitumor immune response.

\section{Discussion}

In the present study, the status and function of B cells in the TLSs surrounding gastric cancer tumors was investigated. Following which it was found that in intratumor TLSs, the proportion of naive $\mathrm{B}$ cells was reduced, while the numbers of $\mathrm{CD} 38^{+} \mathrm{B}$ cells were increased, suggesting clonality and interaction with $\mathrm{T}$ cells. The mRNA expression levels of granzyme and perforin were also found to be increased around TLSs in the resected specimens. These results suggest that local TLSs in gastric cancer may be involved in the anti-tumor immune response.

TLSs are structurally and functionally similar to secondary lymph organs, characterized by B cell follicles, $\mathrm{T}$ cell zones, FDCs, DCs and HEVs within almost any non-lymphoid tissue $(25,26)$. TLSs are also present in the mucosa of the normal stomach, primarily on the muscularis mucosae (27), and chronic inflammation due to persistent $H$. pylori infection is hypothesized to cause TLSs to be organized in the normal gastric mucosa, also called mucosa-associated lymphoid tissue (11). In the present study, it was found that 


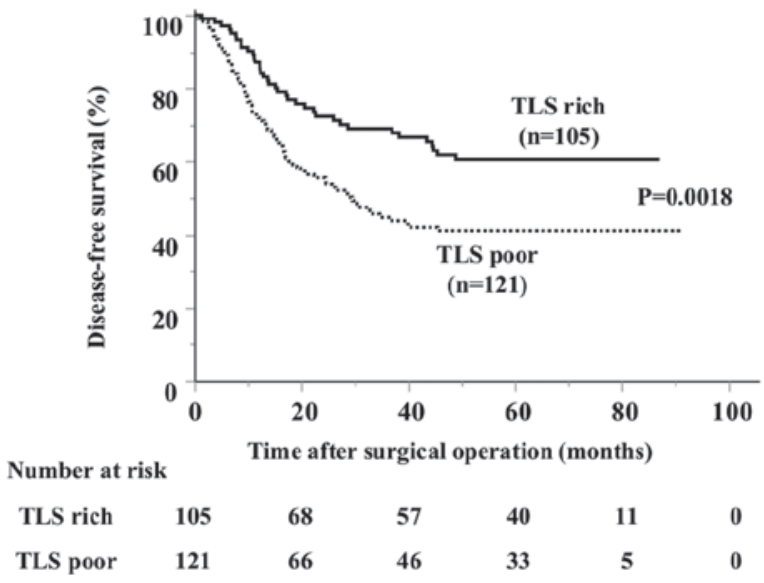

Figure 2. Kaplan-Meier curve of the DFS in patients with gastric cancer stratified by TLSs number. The DFS was significantly longer in the TLS-rich group than in TLS-poor group. TLSs, tertiary lymphoid structures; DFS, disease-free survival.

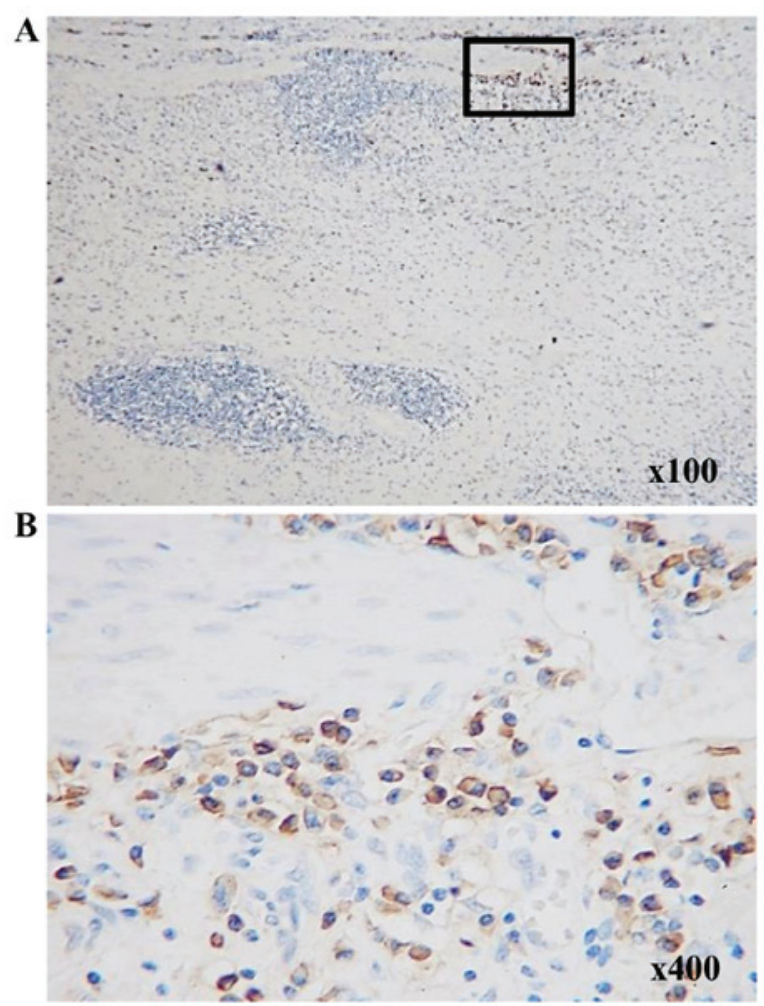

Figure 3. Immunohistochemical staining of $\mathrm{CD}_{138^{+}}$cells in patients with gastric cancer. $\mathrm{CD} 138^{+}$cells are not present within tertiary lymphoid structures at (A) low- and (B) high-power fields. (B) is indicated by the area highlighted in the black rectangle in (A).

$\mathrm{B}$ cells, $\mathrm{T}$ cells and FDCs form aggregates in gastric cancer tissue, an aspect that has been previously reported in greater detail (8), with $\mathrm{CD} 4^{+} \mathrm{T}$ cells occupying the majority of the $\mathrm{CD}^{+} \mathrm{T}$ cell zone, while scattered $\mathrm{CD} 8^{+} \mathrm{T}$ cells were found around the $\mathrm{B}$ cell zone, and the presence of $\mathrm{Bcl}^{+}$, germinal center B cells and HEVs adjacent to the B cell areas. TLS neogenesis and lymphoid organogenesis also share numerous common mechanisms. The mechanism of B cell differentiation has been previously described (28). In brief, generally, in secondary lymphoid organs, antigen-activated B cells from
Table I. Association of TLSs with the clinicopathological features in patients with gastric cancer.

\begin{tabular}{lcccc}
\hline Characteristics & $\begin{array}{c}\text { No. of } \\
\text { patients, } \mathrm{n}\end{array}$ & $\begin{array}{c}\text { TLS } \\
\text { poor, } \mathrm{n}\end{array}$ & $\begin{array}{c}\text { TLS } \\
\text { rich, } \mathrm{n}\end{array}$ & P-value \\
\hline All cases & 226 & 121 & 105 & \\
pT category & & & & \\
T1b-2 & 74 & 44 & 30 & \\
T3-4 & 152 & 77 & 75 & 0.213 \\
pN category & & & & \\
N0-1 & 118 & 64 & 54 & \\
N2-3 & 108 & 57 & 51 & 0.826 \\
pStage & & & & \\
Ib-II & 113 & 62 & 51 & \\
III-IV & 113 & 59 & 54 & 0.689 \\
Location & & & & \\
U & 68 & 34 & 34 & \\
M & 70 & 43 & 27 & \\
L & 88 & 44 & 44 & 0.281 \\
Circumference & & & & \\
Ant & 37 & 22 & 15 & \\
Less & 105 & 52 & 53 & \\
Post & 34 & 17 & 17 & \\
Gre & 39 & 22 & 17 & \\
Circ & 11 & 8 & 3 & 0.536 \\
Histological type & & & & \\
Differentiated & 94 & 50 & 44 & \multirow{2}{\text{Undifferentiated}}{} \\
\hline
\end{tabular}

TLS, tertiary lymphoid structures; U, upper third; M, middle third; L, lower third; Ant, anterior wall; Less, lesser curvature; Post, posterior wall; Gre, greater curvature; Circ circumferential involvement.

naïve B cells enter the GC and differentiate into GC B cells, which subsequently differentiate into plasmablasts and remain active, or transform into memory B cells. Some memory $B$ cells remain in the GC and lymphatic organs, but migrate outside the lymphatic organs and circulate in the blood (29). A similar mechanism is believed to be involved in TLSs $(10,30)$.

In the present study, it was demonstrated that B cell activation occurred in the TLS-rich tumor. The presence of almost all B cell stages, including GC B cells, plasmablasts and numerous memory B cells, was observed in gastric cancer, as previously reported in non-small cell lung cancer (NSCLC) (14). However, PCs were concentrated near the periphery of TLSs, and this has been previously reported in ovarian cancer (31). Indeed, the infiltration of PCs has been controversial. CD138 ${ }^{+}$cells were associated with increased overall survival time in patients with NSCLC (32), whereas CD138 ${ }^{+}$cells were associated with shorter survival in patients with colorectal cancer and invasive ductal breast cancer $(33,34)$. In addition, Germain et al (14) showed that the number of GC-B cells in TLS-rich NSCLC tumors was correlated with the number of PCs able to secrete antibodies against endogenous tumor-associated antigens, such as LAGE-1, NY-ESO-1, P53. Their findings suggest that TLSs 


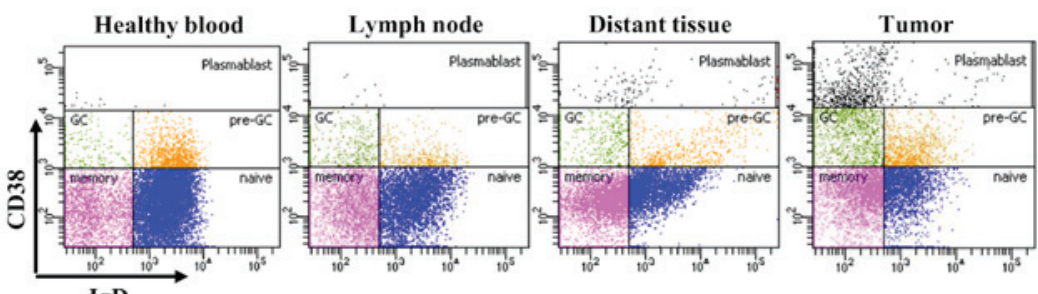

B $(\%)$

IgD

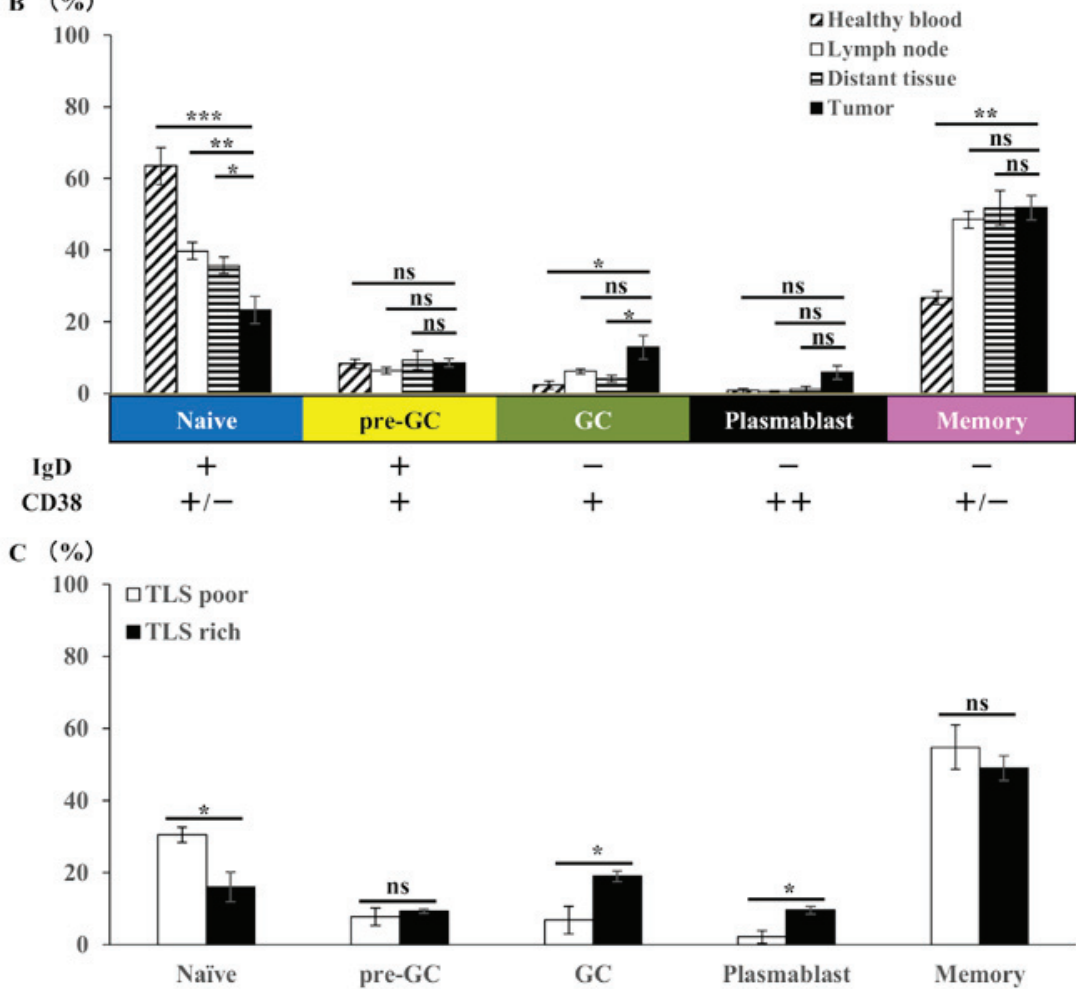

Figure 4. Flow cytometry analysis of $B$ cell subsets in gastric tumor tissues $(n=20)$, compared with lymph nodes $(n=20)$ and distant nontumoral tissues $(n=20)$ from the same patients with gastric cancer and compared with blood $(\mathrm{n}=3)$ from healthy controls. (A) Representative flow cytometry plots and (B) the mean \pm SE of the proportion of each B cell subset among the total CD19+ B cells, which were classified using IgD and CD38 as follows: Naïve B cell, CD38(int)/IgD(+); pre-GC B cell, CD38(int)/IgD(+); GC B cell, CD38(int)/IgD(-); plasmablast, CD38(high)/IgD(-); and memory B cell, CD38(-)/IgD(-). (C) Mean \pm SE of the proportion of each $\mathrm{B}$ cell subset among $\mathrm{CD} 19^{+} \mathrm{B}$ cells within TLS-rich group $(\mathrm{n}=10)$ and TLS-poor group $(\mathrm{n}=10)$. ${ }^{*} \mathrm{P}<0.05$. $\mathrm{ns}$, not significant; SE, standard error; Ig, immunoglobulin; +, positive; -, negative; int, intermediate; TLS, tertiary lymphoid structures.
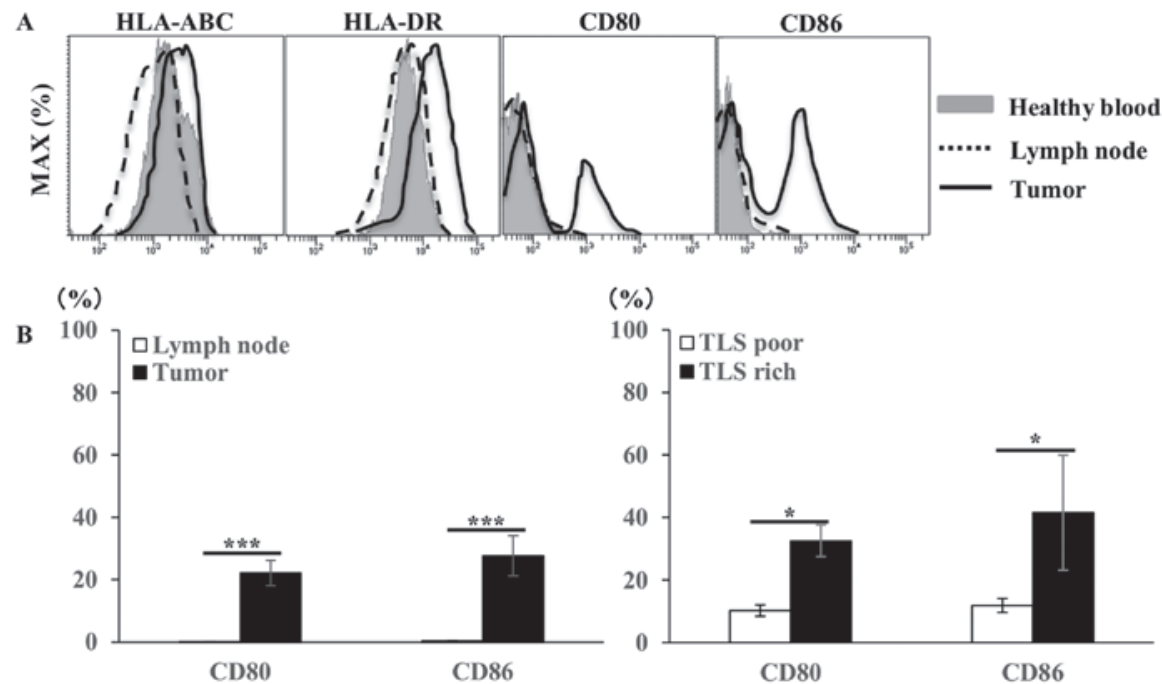

Figure 5. Flow cytometry analysis of B cell phenotype in gastric tumor tissues, compared with lymph nodes from the same patients with gastric cancer and compared with blood from healthy controls. (A) Representative histograms showing the expression of MHC class I (HLA-ABC), MHC class II (HLA-DR), CD80 and CD86 among total the CD20 ${ }^{+}$B cells. (B) The mean \pm SE of the proportion of CD80 and CD86 positive cells among CD20 ${ }^{+}$B cells within lymph nodes $(n=20)$ and tumor tissues $(n=20)$, and within TLS-rich $(n=10)$ and TLS-poor groups $(n=10)$. ${ }^{*}<0.05$. ns, not significant; MHC, major histocompatibility complex; HLA, human leukocyte antigen; SE, standard error; TLS, tertiary lymphoid structures. 

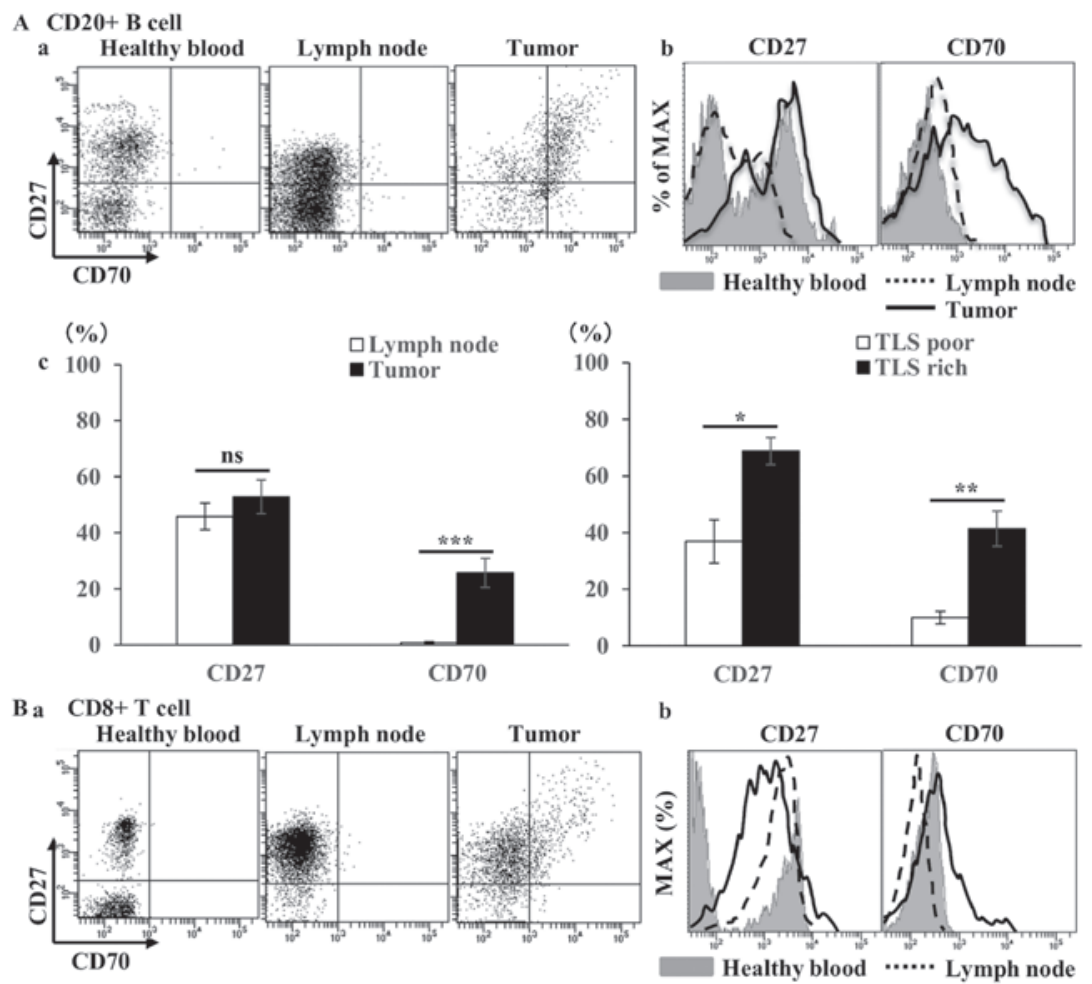

c $(\%)$

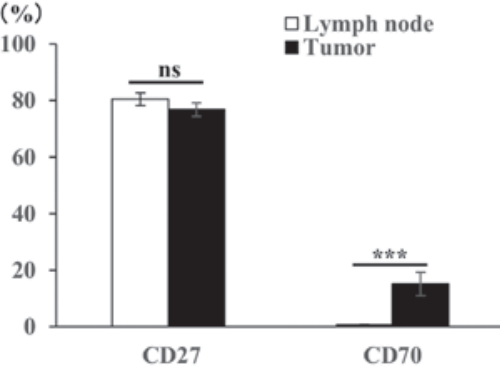

b

b $\quad$ CD27

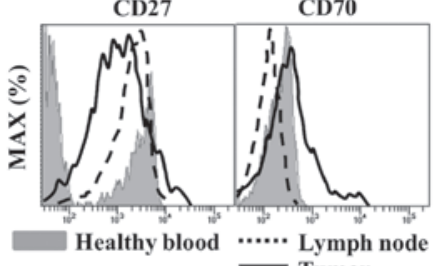

(\%)

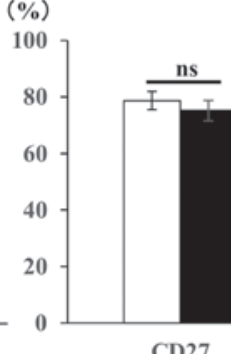

Tum -TLS rich
$\mathrm{CD} 27$

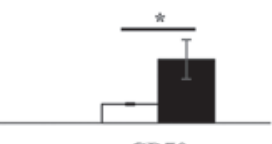

CD70

Figure 6. Flow cytometry analysis of B- and T-cell phenotype in gastric tumor tissues, compared with lymph nodes from the same patients with gastric cancer and compared with blood from healthy controls. (Aa) Representative flow cytometry plots and (b) representative histograms of CD27/CD70 co-stimulatory factors among the total CD20+ B cells. (c) The mean \pm SE of the proportion of CD27 and CD70 positive cells among CD20 $0^{+}$cells within lymph nodes $(n=20)$ and tumors $(n=20)$, and within TLS-rich $(\mathrm{n}=10)$ and TLS-poor groups $(\mathrm{n}=10)$. (Ba) Representative flow cytometry plots and (b) representative histograms of CD27/CD70 costimulatory factors among total $\mathrm{CD}^{+} \mathrm{T}$ cells. (c) The mean $\pm \mathrm{SE}$ of the proportion of CD27 and CD70 positive cells among CD8 ${ }^{+} \mathrm{T}$ cells within lymph nodes ( $\mathrm{n}=20$ ) and tumor tissues $(n=20)$, and with TLS-rich $(n=10)$ and TLS-poor groups $(n=10)$. ${ }^{*} \mathrm{P}<0.05$. ns, not significant; SE, standard error; TLS, tertiary lymphoid structures.

A

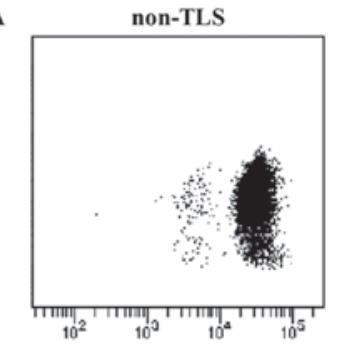

B TLS

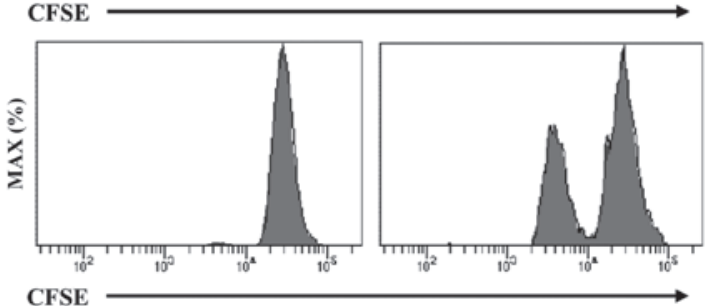

Figure 7. Representative flow cytometry plots and representative histograms of CFSE-labeled $\mathrm{CD}^{+}{ }^{+} \mathrm{T}$ cells for $24 \mathrm{~h}$ after co-culture with B cells isolated from (A) non-TLSs area and (B) TLSs area of tumor tissues. TLS, tertiary lymphoid structures; CFSE, carboxyfluorescein succinimidyl ester. $\begin{array}{lllllllllllllll}\text { Gap } 1 & 2 & 3 & 4 & 5 & 6 & 7 & 8 & 9 & 10 & 11 & 12 & 13 & 14 & 15\end{array}$

A

A

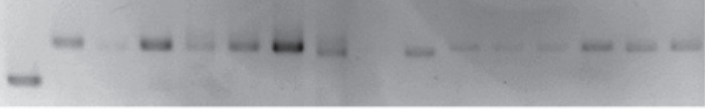

B

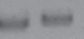

C $-\quad---$

D

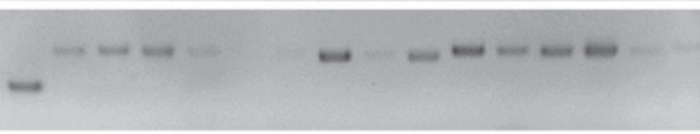

Figure 8. Agarose gel electrophoresis of PCR products. Human heavy and light chain immunoglobulin variable region genes in (A) peripheral blood mononuclear cells from a healthy donor (B-D) in samples from patients with gastric cancer tissues. Specific bands are shown between each group. Lanes 1-3, VH1-VH3-IgG; lanes 4-6, VH1-VH3-IgM; lanes 7-9, vK1/4-vK3; lanes 10-15, VA1-VA6. VH, variable heavy chain; vK, $\kappa$ variable light chain; $\mathrm{VA}, \lambda$ variable light chain. 
A a

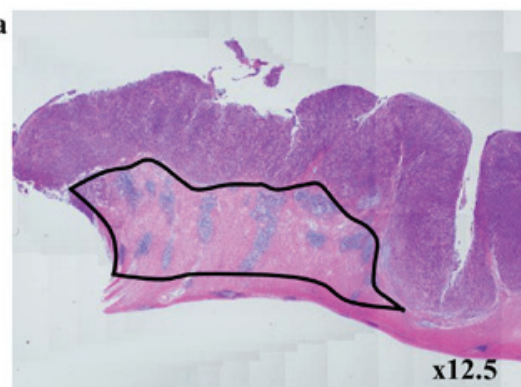

B
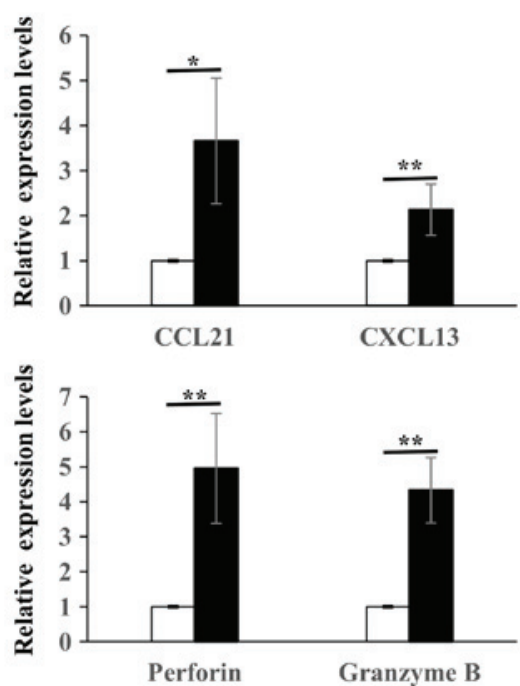

b
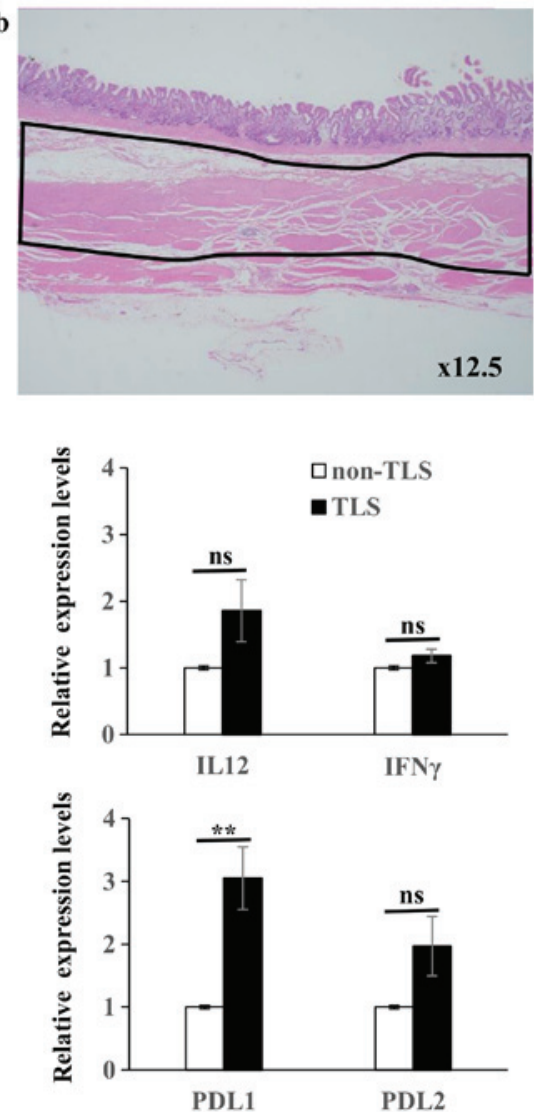

Figure 9. (Aa) Hematoxylin and eosin staining of TLSs area and (b) non-TLSs area within the same specimens; RNA was extracted from inside the black lines. (B) Reverse transcription-quantitative PCR was performed to determine the gene expression level of different genes in TLSs ( $\mathrm{n}=12$ ) vs. non-TLSs ( $\mathrm{n}=12$ ). The results are expressed as arbitrary units (with the expression in non-TLSs defined as 1 unit). The mRNA expression levels of CCL21, CXCL13, perforin, granzyme B, PDL1 was significantly higher in TLSs compared with that in non-TLSs, while the mRNA expression levels of IL12, IFN $\gamma$ and PDL2 were not statistically significant. ${ }^{*} \mathrm{P}<0.05$. ns, not significant; IL, interleukin, IFN, interferon; TLS, tertiary lymphoid structures.

are sites for the local generation of humoral immunity and that PCs may locate towards the tumor to mediate antitumor effects by producing antibodies against tumor-associated antigens. However, in the present study it was revealed that the B cells in TLSs were not PCs, suggesting that the B cells in TLSs have the capacity to present antigens to T cells.

To further investigate the function of APCs, it was found that both $\mathrm{CD} 20^{+} \mathrm{B}$ cells and $\mathrm{CD}^{+} \mathrm{T}$ cells express $\mathrm{CD} 27$ and CD70. The CD27/CD70 co-stimulatory system persists in the effector phase, with the resulting CD27/CD70 interactions driving the survival of effector T cells (35). Furthermore, the ligation of CD27 on B cells to CD70 on CTLs was deemed critical for sustaining the B-cell activation and immunoglobulin synthesis in an antigen-independent manner, as well as for promoting the survival and proliferation of CTLs (36). Arens et al (37) showed that in vivo CD27 ligation by constitutive CD70 on $\mathrm{B}$ cells enhances the primary $\mathrm{CD}^{+} \mathrm{T}$ cell response to tumors; CD27 stimulation results in increased antigen-specific CD8 ${ }^{+}$ $\mathrm{T}$ cell numbers and increased the production of IFN $\gamma$ as well as increased cytotoxicity on a per cell basis. Van de Ven and Borst (38) suggested that the CD27/CD70 co-stimulatory system is geared to promote $\mathrm{B}$ and $\mathrm{T}$ cell responses and particularly the CTL response, which inspires its targeting in cancer immunotherapy.

In the present study, tumor-infiltrating B cells in gastric cancer was semi-clonal, antigen-sensitized, differentiated and activated in tumor tissues and suggests that B cells primarily serve as APCs, which is consistent with previous reports in ovarian cancer and hepatocellular carcinoma $(6,7)$. These findings suggest that the primary function of TLSs may involve cellular immunity rather than humoral immunity. Changes in the BCR gene expression in tumor-infiltrating B cells yielded evidence of oligoclonality, which is a feature of antigen exposure, and it can be surmised that these are enriched B cells with specificity against tumor-associated antigens. In tumor tissues, tumor-infiltrating B cells may be antigen-sensitized and some specific B cell clones may proliferate (14).

TLS formation is promoted by inflammatory cytokine production [e.g. lymphotoxin (LT) $\alpha / \beta$ ], lymphoid chemokine production (e.g. CXCL13 and CCL21) and peripheral node addressin $(\mathrm{PNAd})^{+} \mathrm{HEV}$ development, and through these critical events, B cells, T cells and DCs may participate in the initiation and/or maintenance of TLSs under inflammatory conditions, such as cancer development $(10,39,40)$. Lymphoid organogenesis is under the control of crosstalk between lymphoid tissue inducer cells expressing membrane lymphotoxin (trimeric form LT $\alpha 1 \beta 2$ ) and LT $\beta$-receptor+ lymphoid tissue organizer cells. This interaction leads to the secretion of the lymphoid chemokines CXCL13 and CCL21, which in turn attracts new circulating lymphoid tissue inducer cells, resulting in an amplification loop. CXCL13 and CCL21 then induce the recruitment of $\mathrm{B}$ cells and $\mathrm{T}$ cells, respectively, 


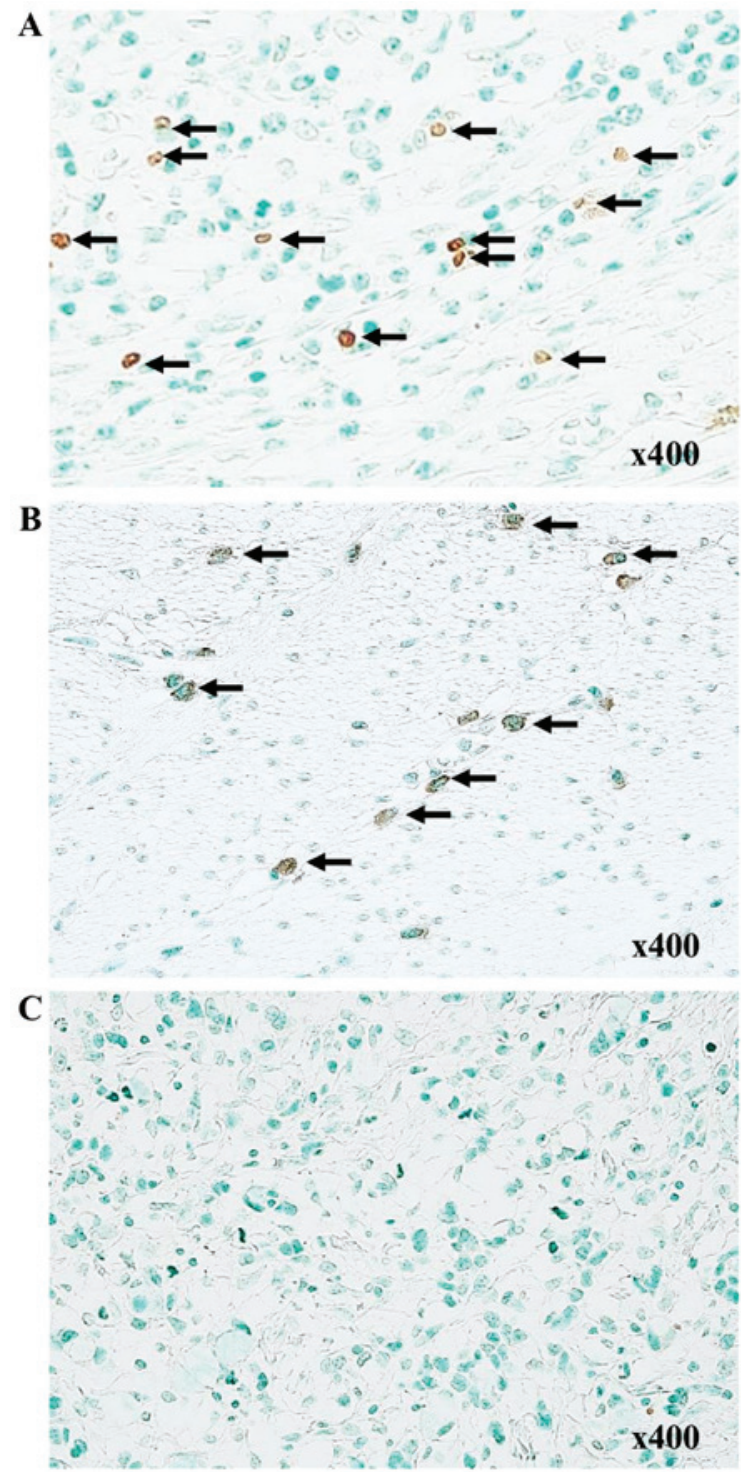

Figure 10. Detection of apoptosis using TUNEL. Apoptotic cells were stained brown. (A and B) TUNEL-positive cells were scattered in TLS-rich group (arrows). (C) Negative TUNEL-positive cells in the TLS-poor group. TLS, tertiary lymphoid structures; TUNEL, terminal deoxynucleotidyl-transferase-mediated dUTP nick end labeling.

into B cell zone and T cell zone of the lymphoid organ (41). $\mathrm{B}$ cells express the chemokine receptor CXCR5 and migrate in response to the expression of CXCL13 by FDCs (13). In the present and in a previous study (8), the presence of HEVs and FDCs in TLSs was demonstrated by immunohistochemical staining. The findings from the present study suggest that CXCL13 and CCL21 play a major role in TLS neogenesis. The aforementioned CXCL13-CXCR5 axis enhances B cell activation by inducing the accumulation of antigens at the $\mathrm{B}$ cell membrane to enhance BCR signaling (42).

The mRNA expression levels of perforin and Granzyme B were found to be increased in TLSs. Tumor-infiltrating B cells might also directly kill tumor cells through antibody-independent mechanisms (43), and B cells can secrete Granzyme B in an IL21 stimulation-dependent manner $(44,45)$, which may potentially have direct cytotoxicity against tumor cells. In hepatocellular cancer, tumor-infiltrating B cells were shown to produce IL12 and IFN $\gamma$ (B cell effector 1 cytokines), suggesting their potential involvement in the facilitation of type 1 cellular immunity (7).

TLSs are induced in response to inflammatory stimuli and develop in any tissue where persistent inflammation occurs as aforementioned (11). Almost all gastric cancers are adenocarcinomas, which are primarily classified into well-differentiated or intestinal type and undifferentiated or diffuse type. The intestinal type is associated with gastritis with atrophy and intestinal metaplasia, whereas the diffuse type originates in pangastritis without atrophy (46). However, there was significant association between tumor location or histological type and TLSs, although the DFS was significantly longer in the TLS-rich group compared with that in the TLS-poor group. These results suggest that the antitumor immune response of TLSs in gastric cancer may be not dependent on histological type but may depend on the extent of TLSs formation.

The present study has some limitations. Firstly, the number of samples was relatively small. This may be due to the fact that $\sim 20 \%$ of the cases in our previous study (8) revealed a strong formation of TLSs, which further reduced the availability of samples for gene or cell collection. Secondly, there were several weaknesses in the analysis of TLSs. It is difficult to distinguish TLSs from other lymphoid structures, such as Crohn's-like Lymphoid Reaction (CLR), as CLR has discrete lymphoid aggregates within the $\mathrm{GC}$ in colorectal cancer, they are mostly located in the muscularis propria and pericolonic adipose tissue beyond the advancing tumor edge, and they could be regarded as CRC-specific ectopic lymphoid structures (47). Lastly, it is important to analyze fibroblastic reticular cells and additional co-stimulatory molecules other than CD27/CD70, such as 4-1BB and OX40, which are associated with the promotion of effector $\mathrm{CD}^{+}$and $\mathrm{CD}^{+} \mathrm{T}$-cell survival, and the formation of $\mathrm{CD}^{+} \mathrm{T}$ cell memory cells (48). Furthermore, it is necessary to clarify the antigens that are recognized by tumor-infiltrating B cells. Therefore, further studies are required to validate the results from the present study. Nevertheless, the presence of TLSs in tumor tissue may induce the development of the antitumor immune response in gastric cancer.

In conclusion it was found that most tumor-infiltrating B cells in gastric cancer exist in the form of TLSs, they are antigen-sensitized, and can differentiate into APCs and proliferate in TLSs but not in lymph nodes. In addition, tumor-infiltrating B cells might primarily function as APCs and may be associated with the increased proliferation and survival of CTLs. These findings suggest that TLSs around the tumor play a crucial role in inducing antitumor CTL proliferation and indicate that TLSs might have an application in immunotherapy for gastric cancer.

\section{Acknowledgements}

Not applicable.

\section{Funding}

No funding was received.

\section{Availability of data and materials}

The datasets used and/or analyzed during the current study are available from the corresponding author on reasonable request. 


\section{Authors' contributions}

YY acquired, analyzed and interpreted the data, and drafted the manuscript. HT made substantial contributions to the conception and design of the study, interpreted the data and revised the manuscript critically. CS, SD, TM, TTa, TTo, and $\mathrm{KM}$ acquired and analyzed the data. $\mathrm{KH}$ and $\mathrm{MO}$ contributed to the conception and design of the study and revised the manuscript critically. All authors read and approved the manuscript.

\section{Ethics approval and consent to participate}

All experimental procedures after 2013 were approved by the Osaka City University Ethics Committee (approval nos. 3138), and all patients provided written informed consent for the collection and analysis of the specimens. On the other hand, all patients up to 2013 provided written informed consent for sample collection and were allowed to withdraw from the study by signing an opt-out form approved by the Osaka City University Ethics Committee (approval nos. 4092).

\section{Patient consent for publication}

Not applicable.

\section{Competing interests}

The authors declare that they have no competing interests.

\section{References}

1. Ramakrishnan R and Gabrilovich DI: Novel mechanism of synergistic effects of conventional chemotherapy and immune therapy of cancer. Cancer Immunol Immunother 62: 405-410, 2013.

2. Lee HE, Chae SW, Lee YJ, Kim MA, Lee HS, Lee BL and Kim WH: Prognostic implications of type and density of tumour-infiltrating lymphocytes in gastric cancer. Br J Cancer 99 $1704-1711,2008$

3. Rosser EC and Mauri C: Regulatory B cells: Origin, phenotype, and function. Immunity 42: 607-612, 2015.

4. Schmidt M, Böhm D, von Törne C, Steiner E, Puhl A, Pilch H, Lehr HA, Hengstler JG, Kölbl H and Gehrmann M: The humoral immune system has a key prognostic impact in node-negative breast cancer. Cancer Res 68: 5405-5413, 2008.

5. Al-Shibli KI, Donnem T, Al-Saad S, Persson M, Bremnes RM and Busund LT: Prognostic effect of epithelial and stromal lymphocyte infiltration in non-small cell lung cancer. Clin Cancer Res 14: 5220-5227, 2008.

6. Nielsen JS, Sahota RA, Milne K, Kost SE, Nesslinger NJ, Watson $\mathrm{PH}$ and Nelson $\mathrm{BH}$ : CD20 $0^{+}$tumor-infiltrating lymphocytes have an atypical CD27- memory phenotype and together with $\mathrm{CD} 8^{+} \mathrm{T}$ cells promote favorable prognosis in ovarian cancer. Clin Cancer Res 18: 3281-3292, 2012

7. Shi JY, Gao Q, Wang ZC, Jian Zhou, Wang XY, Min ZH, Shi YH, Shi GM, Ding ZB, Ke AW, et al: Margin-infiltrating CD20(+) $B$ cells display an atypical memory phenotype and correlate with favorable prognosis in hepatocellular carcinoma. Clin Cancer Res 19: 5994-6005, 2013.

8. Sakimura C, Tanaka H, Okuno T, Hiramatsu S, Muguruma K, Hirakawa $\mathrm{K}$, Wanibuchi $\mathrm{H}$ and Ohira $\mathrm{M}$ : B cells in tertiary lymphoid structures are associated with favorable prognosis in gastric cancer. J Surg Res 215: 74-82, 2017.

9. Neyt K, Perros F, GeurtsvanKessel CH, Hammad H and Lambrecht BN: Tertiary lymphoid organs in infection and autoimmunity. Trends Immunol 33: 297-305, 2012.

10. Dieu-Nosjean MC, Goc J, Giraldo NA, Sautès-Fridman C and Fridman WH: Tertiary lymphoid structures in cancer and beyond. Trends Immunol 35: 571-580, 2014.
11. Winter S, Loddenkemper C, Aebischer A, Räbel K, Hoffmann K, Meyer TF, Lipp M and Höpken UE: The chemokine receptor CXCR5 is pivotal for ectopic mucosa-associated lymphoid tissue neogenesis in chronic Helicobacter pylori-induced inflammation. J Mol Med (Berl) 88: 1169-1180, 2010.

12. Nasr IW, Reel M, Oberbarnscheidt MH, Mounzer RH, Baddoura FK, Ruddle NH and Lakkis FG: Tertiary lymphoid tissues generate effector and memory T cells that lead to allograft rejection. Am J Transplant 7: 1071-1079, 2007.

13. Dieu-Nosjean MC, Giraldo NA, Kaplon H, Germain C, Fridman WH and Sautès-Fridman C: Tertiary lymphoid structures, drivers of the anti-tumor responses in human cancers. Immunol Rev 271: 260-275, 2016.

14. Germain C, Gnjatic S, Tamzalit F, Knockaert S, Remark R, Goc J, Lepelley A, Becht E, Katsahian S, Bizouard G, et al: Presence of B cells in tertiary lymphoid structures is associated with a protective immunity in patients with lung cancer. Am J Respir Crit Care Med 189: 832-844, 2014.

15. Hennequin A, Derangère V, Boidot R, Apetoh L, Vincent J, Orry D, Fraisse J, Causeret S, Martin F, Arnould L, et al: Tumor infiltration by $\mathrm{Tbet}^{+}$effector $\mathrm{T}$ cells and $\mathrm{CD} 20^{+}$ $\mathrm{B}$ cells is associated with survival in gastric cancer patients. Oncoimmunology 5: e1054598, 2015.

16. Schweiger T, Berghoff AS, Glogner C, Glueck O, Rajky O, Traxler D, Birner P, Preusser M, Klepetko W and Hoetzenecker K: Tumor-infiltrating lymphocyte subsets and tertiary lymphoid structures in pulmonary metastases from colorectal cancer. Clin Exp Metastasis 33: 727-739, 2016.

17. Figenschau SL, Fismen S, Fenton KA, Fenton C and Mortensen ES: Tertiary lymphoid structures are associated with higher tumor grade in primary operable breast cancer patients. BMC Cancer 15: 101, 2015.

18. Wirsing AM, Rikardsen OG, Steigen SE, Uhlin-Hansen L and Hadler-Olsen E: Characterisation and prognostic value of tertiary lymphoid structures in oral squamous cell carcinoma. BMC Clin Pathol 14: 38, 2014.

19. Sobin LH, Gospodarowicz MK and Wittekind C (eds): TNM Classification of Malignant Tumours. International Union Against Cancer. Wiley-Blackwell, West Sussex, p336, 2010.

20. Japanese Gastric Cancer Association: Japanese classification of gastric carcinoma: 3rd English edition. Gastric Cancer 14: 101-112, 2011.

21. Tan YS and Lei YL: Isolation of tumor-infiltrating lymphocytes by Ficoll-Paque density gradient centrifugation. Methods Mol Biol 1960: 93-99, 2019.

22. Pascual V, Liu YJ, Magalski A, de Bouteiller O, Banchereau J and Capra JD: Analysis of somatic mutation in five B cell subsets of human tonsil. J Exp Med 180: 329-339, 1994.

23. Welschof M, Terness P, Kolbinger F, Zewe M, Dübel S, Dörsam H, Hain C, Finger M, Jung M, Moldenhauer G, et al: Amino acid sequence based PCR primers for amplification of rearranged human heavy and light chain immunoglobulin variable region genes. J Immunol Methods 179: 203-214, 1995.

24. Livak KJ and Schmittgen TD: Analysis of relative gene expression data using real-time quantitative PCR and the 2(-Delta Delta C(T)) method. Methods 25: 402-408, 2001.

25. Pimenta EM and Barnes BJ: Role of tertiary lymphoid structures (TLS) in anti-tumor immunity: Potential tumor-induced cytokines/chemokines that regulate TLS formation in epithelial-derived cancers. Cancers (Basel) 6: 969-997, 2014.

26. Carragher DM, Rangel-Moreno J and Randall TD: Ectopic lymphoid tissues and local immunity. Semin Immunol 20: 26-42, 2008.

27. Carney JA: Gastric mucosal lymphoid follicles: Histology, distribution, frequency, and etiologic features. Am J Surg Pathol 34: 1019-1024, 2010.

28. Klein U and Dalla-Favera R: Germinal centres: Role in B-cell physiology and malignancy. Nat Rev Immunol 8: 22-33, 2008.

29. Inoue T, Moran I, Shinnakasu R, Phan TG and Kurosaki T: Generation of memory B cells and their reactivation. Immunol Rev 283: 138-149, 2018.

30. Lin L, Hu X, Zhang $\mathrm{H}$ and $\mathrm{Hu} \mathrm{H}$ : Tertiary lymphoid organs in cancer immunology: Mechanisms and the new strategy for immunotherapy. Front Immunol 10: 1398, 2019.

31. Kroeger DR, Milne K and Nelson BH: Tumor-infiltrating plasma cells are associated with tertiary lymphoid structures, cytolytic T-cell responses, and superior prognosis in ovarian cancer. Clin Cancer Res 22: 3005-3015, 2016. 
32. Lohr M, Edlund K, Botling J, Hammad S, Hellwig B, Othman A, Berglund A, Lambe M, Holmberg L, Ekman S, et al: The prognostic relevance of tumour-infiltrating plasma cells and immunoglobulin kappa $\mathrm{C}$ indicates an important role of the humoral immune response in non-small cell lung cancer. Cancer Lett 333: 222-228, 2013.

33. Berntsson J, Nodin B, Eberhard J, Micke P and Jirström K: Prognostic impact of tumour-infiltrating B cells and plasma cells in colorectal cancer. Int J Cancer 139: 1129-1139, 2016.

34. Mohammed ZM, Going JJ, Edwards J, Elsberger B and McMillan DC: The relationship between lymphocyte subsets and clinico-pathological determinants of survival in patients with primary operable invasive ductal breast cancer. Br J Cancer 109: 1676-1684, 2013.

35. Borst J, Hendriks J and Xiao Y: CD27 and CD70 in T cell and B cell activation. Curr Opin Immunol 17: 275-281, 2005.

36. Deola S, Panelli MC, Maric D, Selleri S, Dmitrieva NI, Voss CY, Klein H, Stroncek D, Wang E and Marincola FM: Helper B cells promote cytotoxic $\mathrm{T}$ cell survival and proliferation independently of antigen presentation through CD27/CD70 interactions. J Immunol 180: 1362-1372, 2008.

37. Arens R, Schepers K, Nolte MA, van Oosterwijk MF, van Lier RA, Schumacher TN and van Oers MH: Tumor rejection induced by CD70-mediated quantitative and qualitative effects on effector CD8 ${ }^{+}$T cell formation. J Exp Med 199: 1595-1605, 2004.

38. van de Ven $\mathrm{K}$ and Borst J: Targeting the T-cell co-stimulatory CD27/CD70 pathway in cancer immunotherapy: Rationale and potential. Immunotherapy 7: 655-667, 2015.

39. Germain C, Gnjatic S and Dieu-Nosjean MC: Tertiary lymphoid structure-associated B cells are key players in anti-tumor immunity. Front Immunol 6: 67, 2015.

40. Sautès-Fridman C, Lawand M, Giraldo NA, Kaplon H, Germain C, Fridman WH and Dieu-Nosjean MC: Tertiary lymphoid structures in cancers: Prognostic value, regulation, and manipulation for therapeutic intervention. Front Immunol 7: 407, 2016.
41. Mebius RE: Organogenesis of lymphoid tissues. Nat Rev Immunol 3 : 292-303, 2003.

42. Sáez de Guinoa J, Barrio L, Mellado M and Carrasco YR: CXCL13/CXCR5 signaling enhances BCR-triggered B-cell activation by shaping cell dynamics. Blood 118: 1560-1569, 2011.

43. Lundy SK: Killer B lymphocytes: The evidence and the potential. Inflamm Res 58: 345-357, 2009.

44. Hagn M, Schwesinger E, Ebel V, Sontheimer K, Maier J, Beyer T, Syrovets T, Laumonnier Y, Fabricius D, Simmet T, et al: Human $\mathrm{B}$ cells secrete granzyme $\mathrm{B}$ when recognizing viral antigens in the context of the acute phase cytokine IL-21. J Immunol 183: 1838-1845, 2009.

45. Hagn M, Sontheimer K, Dahlke K, Brueggemann S, Kaltenmeier C Beyer T, Hofmann S, Lunov O, Barth TF, Fabricius D, et al: Human B cells differentiate into granzyme B-secreting cytotoxic B lymphocytes upon incomplete T-cell help. Immunol Cell Biol 90: 457-467, 2012.

46. Crew KD and Neugut AI: Epidemiology of gastric cancer. World J Gastroenterol 12: 354-362, 2006

47. Maoz A, Dennis M and Greenson JK: The Crohn's-like lymphoid reaction to colorectal cancer-tertiary lymphoid structures with immunologic and potentially therapeutic relevance in colorectal cancer. Front Immunol 10: 1884, 2019.

48. Hendriks J, Xiao Y, Rossen JW, van der Sluijs KF, Sugamura K, Ishii N, Borst J, et al: During viral infection of the respiratory tract, $\mathrm{CD} 27,4-1 \mathrm{BB}$, and OX40 collectively determine formation of $\mathrm{CD}^{+}$memory $\mathrm{T}$ cells and their capacity for secondary expansion. J Immunol 175: 1665-1676, 2005.

(i) $\Theta$ This work is licensed under a Creative Commons Attribution-NonCommercial-NoDerivatives 4.0 International (CC BY-NC-ND 4.0) License. 